\title{
Land cover changes and forest landscape evolution (1985-2009) in a typical Mediterranean agroforestry system (high Agri Valley)
}

\author{
T. Simoniello, R. Coluzzi, V. Imbrenda, and M. Lanfredi \\ IMAA, Istituto di Metodologie per l'Analisi Ambientale, CNR, C.da S. Loja, Z.I., 85050, Tito Scalo (PZ), Italy \\ Correspondence to: V. Imbrenda (vito.imbrenda@imaa.cnr.it)
}

Received: 11 July 2014 - Published in Nat. Hazards Earth Syst. Sci. Discuss.: 25 August 2014

Accepted: 13 April 2015 - Published: 12 June 2015

\begin{abstract}
The present study focuses on the transformations of a typical Mediterranean agroforestry landscape of southern Italy (high Agri Valley - Basilicata region) that occurred over 24 years. In this period, the valuable agricultural and natural areas that compose such a landscape were subjected to intensive industry-related activities linked to the exploitation of the largest European onshore oil reservoir. Landsat imagery acquired in 1985 and 2009 were used to detect changes in forest areas and major land use trajectories. Landscape metrics indicators were adopted to characterize landscape structure and evolution of both the complex ecomosaic (14 land cover classes) and the forest/non-forest arrangement. Our results indicate a net increase of $11 \%$ of forest areas between 1985 and 2009. The major changes concern increase of all forest covers at the expense of pastures and grasses, enlargement of riparian vegetation, and expansion of artificial areas. The observed expansion of forests was accompanied by a decrease of the fragmentation levels likely due to the reduction of small glades that break forest homogeneity and to the recolonization of herbaceous areas. Overall, we observe an evolution towards a more stable configuration depicting a satisfactory picture of vegetation health.
\end{abstract}

\section{Introduction}

The distinctive character of Mediterranean agro-forestry systems is the complex assemblage of different land covers resulting from a millenary history of man-made modifications (Antrop, 2004). Generally these are composed of agricultural fields, sparsely urbanized areas (roads, rural districts, etc.), and heterogeneous forests where a variety of vegetation types are aggregated according to diverse extents, shapes, and con- nectivity levels (Lafortezza et al., 2010). In addition, in the last decades the traditional composition and arrangement of Mediterranean landscapes have been significantly changed by urbanization, industrialization, logging, agricultural policies (e.g., European Common Agricultural Policy), and climate change effects (Grove and Rackham, 2001; Tanrivermis, 2003; Weber et al., 2005; FAO, 2014; Salvati et al., 2014).

In this context it is important to develop sustainable land management strategies that incorporate forest planning. Since the nineteenth century the main conceptual approach to forest planning considers forest landscapes not only for the purpose of providing wood and timber (Farcy, 2004) but also as a precious container of several ecosystem services and functions (conservation of biodiversity; hydrogeological risk protection; center of tourism and recreational activities; and production of non-wood products such as mushrooms, fodder, and honey) to be sustained over time. Therefore the definition of a framework of sound principles to plan a sustainable governance of forest resources holds a key role.

The new emerging paradigm, the so-called SFM (sustainable forest management; Szaro et al., 2000), is based on the integration of multiple forest values. In Italy, forest landscape management plans have recently been gaining importance as intermediate tools between national/regional forest management plans and forest regulations applied at farm level (Paletto et al., 2012).

Effective tools to support these plans have to provide updated observations to characterize forest evolution. Satellite data have a well-established history in informing forest management/inventory. In particular, Landsat images have been largely applied to forest monitoring and studies because they represent a trade-off among the need of high spatial resolu- 
tion $(30 \mathrm{~m})$, reasonable revisiting frequency (16 days), and availability of long time series (since July 1972) to carry out multitemporal analyses (Collins and Woodcock, 1996; Borrelli et al., 2014; Mancino et al., 2014).

The evolution of forests can be advantageously explored through adopting a landscape ecological approach (Lafortezza et al., 2013) that relies on the identification of ecological patterns generated by mutual interactions between anthropogenic activities and natural processes (Ingegnoli, 2002). By using landscape metrics it is possible to quantify parameters linked to geographical patterns generated by land use/land cover dynamics. In fact, metrics are used in a wide range of disciplines with different applications, such as water quality (Uuemaa et al., 2007), biodiversity (Schindler et al., 2008), and land degradation (Imbrenda et al., 2014). Recently they have been successfully applied also to evaluate forest health status (State of Europe's Forests, Forest Europe, UNECE and FAO, 2011).

In particular, information obtained from landscape metrics can be very valuable for the improvement of silvicultural prescriptions and baselines for forest management, as well as to highlight effects of implemented actions (Sano et al., 2009; Reddy et al., 2013; Costa et al., 2014; Paliwal and Mathur, 2014).

The multitemporal analysis performed in this study (19852009) attempted to investigate changes that occurred in the landscapes of the high Agri Valley (Basilicata - southern Italy), a typical example of Mediterranean landscape. This area is characterized by a consistent presence of agricultural activities in predominantly hilly environments and by a unique forest heritage with rich biodiversity that have stimulated tourism growth. Contextually, a significant increase in anthropogenic disturbance has occurred since the 1990s due to the exploitation of the largest European onshore oil reservoir and to the consequently induced activities.

Due to these peculiar conditions our purpose was to analyze the landscape structure and evolution of the area during the investigated period with a focus on forests.

To this aim land cover maps (14 classes) were created for the reference years and subsequently recoded in binary forest/non-forest maps. Then, in order to evaluate the ecological stability of the area, we analyzed the results obtained by applying landscape metrics indicators on the abovementioned maps.

Especially when used in multitemporal studies (Fichera et al., 2012), landscape metrics can capture the land use processes potentially connected to adverse impacts (forest loss and fragmentation), or positive environmental conditions (forest gain and increasing forest connectivity).

In order to correctly interpret our results, we allowed the analysis of possible anthropogenic or environmental driving factors. As we will show in the following, the inspection of the detected changes suggested to us to use metrics to evaluate the effects of different management practices, analyzing public- and private-ownership areas separately so as

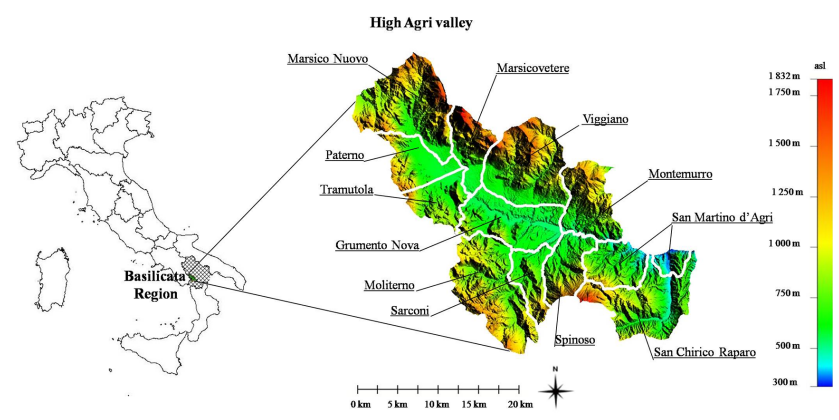

Figure 1. Location of the study area within the Basilicata region (southern Italy). The zoom shows the administrative limits of the municipalities of the high Agri Valley overlapped on the digital elevation model (DEM) of the area provided by the Basin Authority of the region at $20 \mathrm{~m}$ resolution.

to understand how forest tenure regimes may influence arrangement, spatial heterogeneity, and ecological functionality of vegetated classes (Botequilha Leitato and Ahern, 2002; Blondel et al., 2010; Lafortezza et al., 2013).

\section{Materials}

\subsection{Study area}

The high valley of the Agri River is an intermountain basin located in the southern Apennines (Basilicata, Italy), covering about $725 \mathrm{~km}^{2}$ (Fig. 1).

The local climate is characterized by cold-humid winters and hot-dry summers, as occurs in typical Mediterranean regions (http://www1.inea.it/otris/file/clima_txt.htm, last access: 10 July 2014). According to Cantore et al. (1987) the total amount of annual rainfall is around $1100 \mathrm{~mm}$, which would usually be sufficient to allow for normal plant life. However precipitation shows a high annual excursion (more than $800 \mathrm{~mm}$ ), and summer droughts are likely responsible for the physiognomy of vegetation types, sometimes predisposing them to parasitic attacks.

The area is characterized by human settlements that are organized in many sparsely urbanized (12 municipalities) and rural areas. The latter, especially in bottom valleys, are devoted to intensive agriculture thanks to the presence of water and rich soils.

Because of the high elevation variability that characterizes the whole area, it is possible to distinguish different vegetation environments containing the most important forest formations typical of the southern Apennines Mountains (INEA, 2006). The prevalent types of forest are composed of deciduous oak wood and turkey oak wood.

In mountainous flat areas located above $1000 \mathrm{~m}$, the thermophilic beech forest, typical of the southern Apennines, dominates especially in environments with appropriate levels of edaphic and atmospheric humidity. Noticeably, there 
is a considerable presence of chestnut coppice managed, primarily devoted to timber production and secondarily to obtain fruits. Grass and pasture, as essential components of the Mediterranean agro-forestry systems, are widely scattered all over the region and ensure the maintenance of bovine livestock farming (http://dati-censimentoagricoltura.istat.it/, last access: 10 July 2014).

The unique and valuable environmental characteristics of this area come from the presence of the "Appennino Lucano, Val d'Agri, Lagonegrese" National Park and several protected areas (SIC - site of community importance; SPA special protection area) with a wide range of flora and fauna biodiversity. The wealthy fauna includes the occasional presence of wild boars and wolves in addition to more common species adapted to anthropic landscapes and conditions such as the fox, badger, porcupine, and otter (Carone et al., 2012).

Currently no evident phenomena of land degradation are present in the area (Lanfredi et al., 2015).

Both agricultural and forest sectors fulfill a quite important role within the economy of the valley. In the past, the economy was predominantly wood-based, encompassing production of timber and non-wood products such as mushrooms and undergrowth fruits. More recently, we have observed the escalation of interests and activities around the oil reservoir, which is the largest in Italy and considered as a strategic resource for the overall national energy sector.

\subsection{Data}

We used satellite data acquired by the Thematic Mapper (TM) sensor flying on the Landsat 5 satellite.

In particular, we processed and analyzed two images available for the study area (188 path and 32 row GTCE), acquired on 10 August 1985 and 27 July 2009 with a spatial resolution of 30 meters. A 24-year interval was considered suitable to capture significant changes in forest areas and to assess the evolution of composition and configuration of the investigated covers; dry-season images were selected for limiting the presence of cloud cover.

Furthermore, the Forest Map of Regione Basilicata was used as ancillary information (INEA, 2006; Costantini et al., 2011). It was elaborated by the National Institute of Agricultural Economics (INEA) in order to enhance the spatial distribution of the forest categories at different aggregation levels. The map, implemented by means of extensive field surveys and photo-interpretation, is provided in shape data format and includes different parameters, such as the physiognomic class, the species composition, and their relative abundance, type, and degree of accessibility.

\section{Methods}

\subsection{Land cover maps and forest persistence}

The two selected Landsat images were firstly preprocessed applying the transformation of digital numbers into radiance units and then into reflectance using the NASA-GSCF calibration coefficients (Chander and Markham, 2003; Barsi et al., 2007).

In order to detect and interpret the most important changes that occurred in the investigated period, we produced land cover maps for the reference years. This was performed by using the multispectral clustering technique K-means (Richards and Jia, 1996; Brivio et al., 2006), which enables a preliminary partition of the area separating natural from anthropogenic covers and to iteratively identifying macroclasses. Successively, we refined the obtained classifications using training areas identified on the basis of spectral information, ancillary data derived from field surveys and the Forest Map of Regione Basilicata in a supervised classification (Maximum Likelihood). Ultimately, we defined a complex ecomosaic of 14 classes for each year. From these, we derived also the following maps:

- forest/non-forest maps obtained by aggregating the 14 classes in a binary map;

- complex ecomosaic maps obtained by splitting forest classes into private- and public-ownership areas. This is the result of the intersection between the 14 classes of ecomosaics and the available file of public-forest boundaries.

Land cover changes that occurred in the period examined were firstly pointed out by comparing the percentage of the landscape area occupied by each cover. In particular, as for the 14 classes of ecomosaics, a transition matrix between initial and final distributions was evaluated to provide evidence of alterations in the spatial patterns that synthesize the most important land cover trajectories emerging in the period investigated.

To characterize forest areas, we evaluated different fragmentation levels using a satellite-derived index of cover density (D), based on NDVI (normalized difference vegetation index). NDVI is one of the most used vegetation indices, considered as a proxy for plant biomass and vegetation activity (Rouse et al., 1974), and it is calculated as follows:

$\mathrm{NDVI}=\frac{\mathrm{NIR}-\mathrm{RED}}{\mathrm{NIR}+\mathrm{RED}}$,

where NIR and RED are respectively the near-infrared and red channels of the electromagnetic spectrum, corresponding to bands 4 and 3 of the TM sensor.

In this study we derived NDVI from both the images and evaluated the relative density $D$ for each cover class for both 
the years 1985 and 2009 according to the following formula:

$D=\frac{\mathrm{NDVI}-\mathrm{NDVI}_{\min }}{\mathrm{NDVI}_{\max }-\mathrm{NDVI}_{\min }}$,

where $\mathrm{NDVI}_{\max }$ and $\mathrm{NDVI}_{\min }$ represent the maximum and minimum NDVI value for each forest class.

Afterwards, the values of the cover density index were classified into four ranges $(<20,20-50,50-80,>80 \%)$.

Integration, spatial analysis, and any calculations were carried out in the GIS environment (QGIS 1.8, GRASS 6.4.2). The geographic information was projected to WGS84 UTM zone 33 .

\subsection{Landscape metrics}

The evaluation of the landscape structure was performed using metrics indicators, i.e., the core of landscape ecology. Landscape metrics focus on the whole landscape considered as a mix of mutually interacting anthropic and natural covers and allow both landscape composition and configuration to be analyzed. Composition refers to the variety and relative abundance of patch types within the ecomosaic and is typically quantified by diversity indices; configuration is linked to the spatial arrangement and the functional connectivity of the patches (McGarigal et al., 2009).

We computed landscape metrics from the land covers obtained according to the methodology described in Sect. 3.1. This enabled us to determine the spatial relationships among patches within the ecomosaics and how the identified patterns change in the analyzed period (Jaeger, 2000). In particular, metrics greatly enhance our knowledge on how the growing impact of anthropogenic activities occurred in the study area during the reference period might have affected the ecosystem's ability to provide services and functions (Nagendra et al., 2004), facilitating also the interpretation of potential ecological consequences.

Moreover, in order to evaluate landscape properties under different forest management, we applied landscape metrics to forest classes of the ecomosaics, differentiating privateand public-ownership areas.

To this aim, we selected a minimally redundant and easily interpretable set of metrics indicators (Table 1), computed using public domain software FRAGSTAT 4.1 (McGarigal et al., 2012).

\section{Results and discussions}

\subsection{Analysis of land cover transitions (1985-2009)}

\subsubsection{Complex ecomosaic: 14 classes}

Figure 2 shows the 14 classes of land cover maps derived from Landsat TM data for the years 1985 and 2009: eight forest covers (beech forests, chestnut forests, coniferous forests, oak wood, turkey oak wood, manna ash and hophornbeam, riparian vegetation, and plantations including arboriculture plantations and reforestation with exotic species), one shrublike cover (shrublands), one herbaceous cover (grass and pasture areas), three non-vegetated covers (non-vegetated areas including mainly artificial surfaces and bare soil, burned areas, and water bodies), and one agricultural area. Table 2 shows land cover classes and the corresponding acronyms adopted in this work. The overall classification accuracy for both the land cover maps is $85 \%$.

At first glance it is evident that the underlying structures of the area have remained essentially unchanged during the investigated period (about $92 \%$ of the total study area). This is confirmed by the transition matrix obtained by calculating the distribution of the identified 14 classes for the investigated years (Table 3 ). The main diagonal, representing the proportion of each class that did not change through time, is populated by percentage values approaching $100 \%$ with the exception of grass and pasture (GP), non-vegetated areas (NVAs), and plantations (Pl).

In the analyzed period, the major change concerned GP areas. In fact, we observed the breakup of this cover (only $58 \%$ remains unchanged) that significantly receded to the advantage of almost all the forest classes configuring a scenario of positive evolution of forest covers.

Covers benefitting most from this process are mainly oak wood (Oa), turkey oak wood (TOa), coniferous forest classes (Co), shrublands (Sh), and riparian vegetation (Ri). The last one exhibits an enlargement that is small in absolute terms but very significant if compared with the limited size of the examined class in 1985 (about $+18 \%$ ). Moreover also beech forests $(\mathrm{Be})$ show a slight increase, and chestnut forests $(\mathrm{Ch})$ remain substantially stable.

NVAs slightly expanded (about $100 \mathrm{ha}$ ). This is a low but worthy increase because it comes from the positive balance between two different phenomena: from one hand the growth of industrial areas (mostly coinciding with the building of the oil/gas pre-treatment plant in the municipality of Viggiano) to the detriment of agricultural areas (AAs), on the other the conversion of some bare soil areas in predominantly natural covers.

The small loss of AAs (about 270 ha predominantly occupied by arable land) involving mountainous and steep sloping areas is well explained by the crisis of the agriculture sector in marginal areas and the consequent land abandonment as occurred in many regions of southern Europe (Kosmas et al., 2015). Moreover, the burned areas class (BAs) covering about 100 ha in 1985 had disappeared in 2009. Examples of the above-discussed land cover changes are shown in Fig. 3.

\subsubsection{Binary ecomosaic: forest/non-forest}

The aggregation in forest/non-forest areas allowed us to investigate the modifications related to forest classes cover as a whole (Fig. 4). Forest class includes eight forest covers (beech forests, chestnut forests, coniferous forests, oak 
Table 1. Landscape metrics indicators selected for evaluating the study area composition and configuration at landscape and class level.

\begin{tabular}{|c|c|}
\hline Name & escription \\
\hline $\mathrm{NP}$ & $\begin{array}{l}\text { Number of patches at the class or landscape level. } \\
\qquad \mathrm{NP}=\sum_{i=1}^{n} t_{i} \\
\text { where } n \text { is the number of patch } t_{i} \text { of a single class or of a landscape. }\end{array}$ \\
\hline Gyrate & $\begin{array}{l}\text { Extent of each patch, i.e., how far across the landscape a patch extends its reach, given by the mean } \\
\text { distance between cells in a patch. All other things equal, the larger the patch, the larger the radius of } \\
\text { gyration. Similarly, holding area constant, the more extensive the patch (i.e., elongated and less compact), } \\
\text { the greater the radius of gyration } \\
\qquad \text { Gyrate }=\frac{\sum_{m=1}^{k} d_{i j m}}{k} \text {, } \\
\text { where } d_{i j m} \text { is the distance of each cell from the centroid of the patch } i j \text { and } k \text { is total number of cells that } \\
\text { compose them. }\end{array}$ \\
\hline $\begin{array}{l}\text { Mean patch size } \\
\text { (MPS) }\end{array}$ & $\begin{array}{l}\text { The average area of patches comprising a landscape mosaic } \\
\qquad \operatorname{MPS}=\frac{\sum_{j=1}^{n} a_{i j}}{n_{i}} \\
\text { where } a_{i j} \text { is the area (ha) of patch } i j ; n \text { is the patch number belonging to class } i .\end{array}$ \\
\hline Shape & $\begin{array}{l}\text { Shape index is a measure of patch geometric complexity, and it is given as the patch perimeter divided by } \\
\text { the patch perimeter divided by the patch perimeter for a patch square of the same size. The index equals } 1 \\
\text { for square patches of any size and increases without limit as the patch becomes increasingly non-square } \\
\text { (i.e., more geometrically complex). } \\
\qquad \text { Shape }=\frac{p_{i j}}{\min p_{i j}} \\
\text { where } p_{i j} \text { is the perimeter of patch } i j \text {; } \min p_{i j} \text { is the minimum perimeter of patch } i j \text { in terms of number } \\
\text { of cell edges; } n_{i} \text { is the number of patch. }\end{array}$ \\
\hline Cohesion & $\begin{array}{l}\text { Cohesion index is a measure of the physical connectedness of the corresponding patch type. It is an area- } \\
\text { weighted mean perimeter / area ratio, invariant to changes in the cell size. It is bounded } 0-100 \text {. Its value } \\
\text { increases if the patch is more aggregated in its distribution, i.e., more physically connected; it is given as } \\
0 \text { if a class consists of a single patch. } \\
\qquad \text { Cohesion }=\left(1-\frac{\sum_{j=1}^{n} p_{i j}}{\sum_{j=1}^{n} p_{i j} \sqrt{a_{i j}}}\right)\left(1-\frac{1}{\sqrt{N}}\right)^{-1}(100), \\
\text { where } p_{i j} \text { is the perimeter (m) and } a_{i j} \text { is the area of patch } i j ; N \text { is the total number of cells. }\end{array}$ \\
\hline ShDI & $\begin{array}{l}\text { Shannon's diversity index is a measure of diversity in community ecology, applied to landscapes. Its value } \\
\text { is } 0 \text { when the landscape contains only } 1 \text { patch (i.e., no diversity); it increases as the number of differ- } \\
\text { ent patch types increases and/or the proportional distribution of area among patch types becomes more } \\
\text { equitable. } \\
\qquad \mathrm{ShDI}=-\sum_{i=1}^{m}\left(P_{i} \ln P_{i}\right) \text {, } \\
\text { where } P_{i} \text { is the proportion of the landscape occupied by patch type (class) } i .\end{array}$ \\
\hline ShEI & $\begin{array}{l}\text { Shannon's evenness index is expressed as the ShDI divided by the logarithm of the number of patch } \\
\text { types. ShEI }=0 \text { when the landscape contains only one patch (i.e., no diversity) and approaches } 0 \text { as the } \\
\text { distribution of area among the different patch types becomes increasingly uneven (i.e., dominated by one } \\
\text { type); ShEI }=1 \text { when distribution of area among patch types is perfectly even (i.e., proportional abundances } \\
\text { are the same). } \\
\qquad \text { ShEI }=\frac{-\sum_{i=1}^{m}\left(P_{i} \ln P_{i}\right)}{\ln m}, \\
\text { where } P_{i} \text { is the proportion of the landscape occupied by patch type (class) } i ; m \text { is the number of patch } \\
\text { types (classes) present in the landscape. }\end{array}$ \\
\hline ENN & $\begin{array}{l}\text { Euclidean nearest neighbor is the Euclidean measure of the distance (m) from a patch to the nearest neigh- } \\
\text { boring patch of the same type, based on shortest edge-to-edge distance (from cell center to cell center) } \\
\qquad \mathrm{ENN}=h_{i j} \text {, } \\
\text { where } h_{i j} \text { is distance (m) from patch } i j \text { to nearest neighboring patch of the same type (class) }\end{array}$ \\
\hline
\end{tabular}




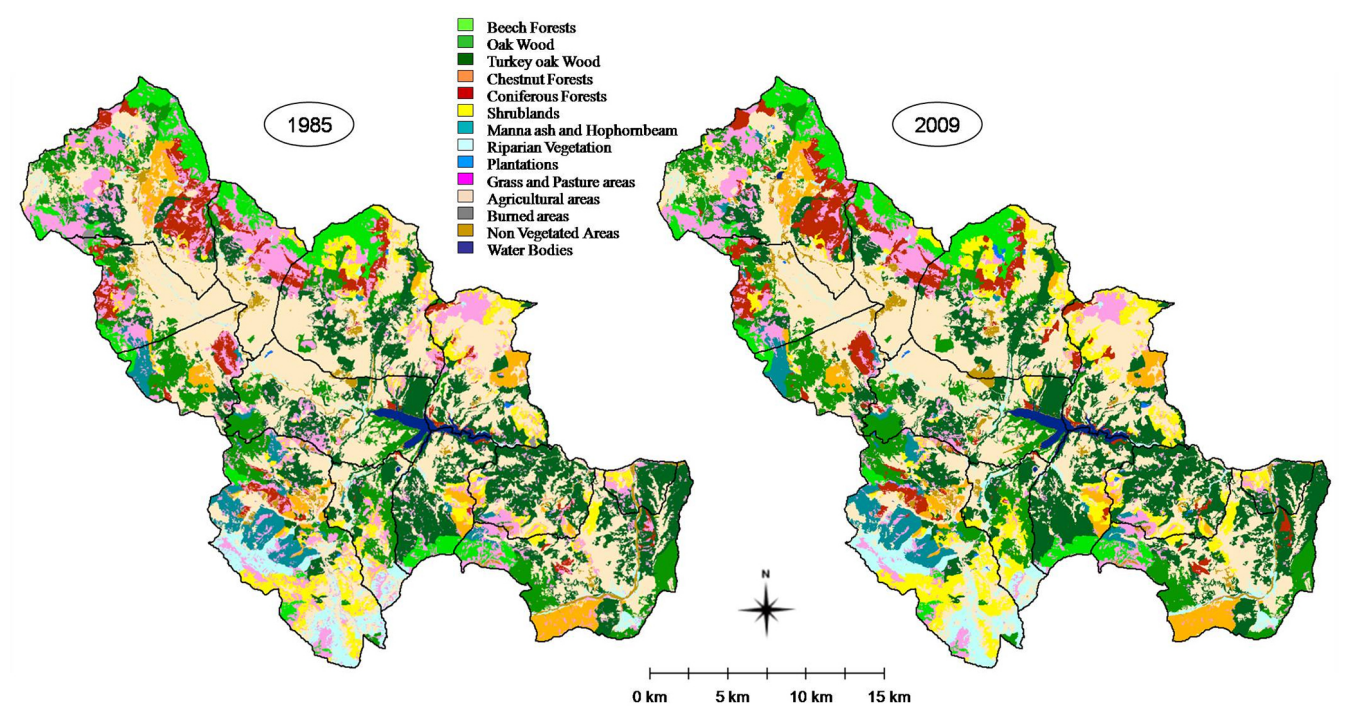

Figure 2. Land cover maps for the years 1985 and 2009 derived from Landsat TM data.

Table 2. Land cover classes and corresponding acronyms.

\begin{tabular}{lrlr}
\hline Land cover class & Acronym & Land cover class & Acronym \\
\hline Beech forests & $\mathrm{Be}$ & Manna ash and hophornbeam & $\mathrm{MH}$ \\
Oak wood & $\mathrm{Oa}$ & Riparian vegetation & $\mathrm{Ri}$ \\
Turkey oak wood & $\mathrm{TOa}$ & Plantations & $\mathrm{Pl}$ \\
Chestnut forests & $\mathrm{Ch}$ & Grass and pasture areas & $\mathrm{GP}$ \\
Coniferous forests & $\mathrm{Co}$ & Agricultural areas & AAs \\
Shrublands & $\mathrm{Sh}$ & Burned areas & $\mathrm{BAs}$ \\
Non-vegetated areas & NVAs & Water bodies & WBs \\
\hline
\end{tabular}

wood, turkey oak wood, manna ash and hophornbeam, riparian vegetation, and plantations including arboriculture plantations and reforestation with exotic species), shrub-like cover (shrublands) and herbaceous cover (grass and pasture areas); non-forest class includes three non-vegetated covers (non-vegetated areas including mainly artificial surfaces and bare soil, burned areas, water bodies) and the agricultural area.

Forest class shows a net increase of $11 \%$ (about 5000 ha) as a result of transitions from $(+12 \%)$ and towards $(-1 \%)$ the non-forest class. This increase is mostly due to past and recent afforestation works and to the natural evolution of forest covers.

Within the non-forest class the areas located in the valley bottom, mainly devoted to agricultural use, remain substantially unchanged.

\subsection{Landscape metrics analysis}

\subsubsection{Complex ecomosaic: 14 classes}

The landscape analysis of the ecomosaic composed of 14 covers was carried out by using the indices described in the Table 1.

Starting from the landscape level analysis (Table 4), the indices SHDI and SHEI appear similar at the two different dates. Furthermore, SHDI values for both the years indicate landscapes with an adequate level of diversity in terms of different cover types that, however, maintain a moderate level of spatial distribution (SHEI) as expected for complex Mediterranean ecosystems (Simoniello et al., 2006). We also observe a reduction for NP that can be ascribed to the decrease of less densely vegetated areas within the main forest types between 1985 and 2009. On average, patches preserve the same degree of complexity with respect to the size (shape), but extensiveness/compaction increases (gyrate). Lastly, landscapes show for both the analyzed years a relatively appreciable level of connectedness (cohesion).

At class level the results of the computed metrics are shown only for natural classes in Fig. 6 . 
Table 3. Transition matrix. Percentages values are computed on the area occupied by each class in 1985. Bold in the main diagonal represents the proportion of stable lands in the analyzed period (1985-2009). (Abbreviations are shown in Table 2).

\begin{tabular}{lrrrrrrrrrrrrrr}
\hline \multicolumn{10}{c}{2009} \\
\hline Class & Be & Oa & TOa & Ch & Co & Sh & MH & Ri & Pl & GP & AAs & BAs & NVAs & WBs \\
\hline Be & $\mathbf{9 9 . 4 0}$ & 0 & 0 & 0 & 0.30 & 0 & 0 & 0 & 0 & 0.24 & 0 & 0 & 0.06 & 0 \\
Oa & 0 & $\mathbf{9 8 . 6 3}$ & 0 & 0 & 0.13 & 0 & 0 & 0 & 0 & 1.01 & 0.23 & 0 & 0 & 0 \\
TOa & 0 & 0.01 & $\mathbf{9 8 . 2 9}$ & 0 & 0.09 & 0 & 0 & 0 & 0 & 1.44 & 0.10 & 0 & 0.07 & 0 \\
Ch & 0 & 0 & 0 & $\mathbf{9 8 . 6 1}$ & 0 & 0 & 0 & 0 & 0 & 1 & 0.24 & 0 & 0.15 & 0 \\
Co & 0 & 0.01 & 0 & 0 & $\mathbf{9 9 . 2 9}$ & 0 & 0 & 0 & 0 & 0.70 & 0 & 0 & 0 & 0 \\
Sh & 0 & 0 & 0 & 0 & 0.90 & $\mathbf{9 7 . 1 3}$ & 0 & 0 & 0 & 1.82 & 0 & 0 & 0.15 & 0 \\
MH & 0 & 0 & 0 & 0 & 0.32 & 0 & $\mathbf{9 9 . 1 2}$ & 0 & 0 & 0.56 & 0 & 0 & 0 & 0 \\
Ri & 0 & 0 & 0 & 0.01 & 0.06 & 0 & 0 & $\mathbf{9 8 . 5 8}$ & 0 & 1.01 & 0.34 & 0 & 0 & 0 \\
Pl & 0 & 0 & 0 & 0 & 0 & 0 & 0 & 0 & $\mathbf{9 5 . 9 4}$ & 4.06 & 0 & 0 & 0 & 0 \\
GP & 0.88 & 4.32 & 8.92 & 1.06 & 7.81 & 12.49 & 1.82 & 3.04 & 0.65 & $\mathbf{5 8 . 3 3}$ & 0.44 & 0 & 0.23 & 0.01 \\
AAs & 0 & 0.07 & 0.02 & 0 & 0 & 0.01 & 0 & 0.03 & 0.02 & 0.15 & $\mathbf{9 8 . 2 5}$ & 0 & 1.45 & 0 \\
BAs & 5.83 & 2.96 & 1.71 & 0 & 8.89 & 18.58 & 0 & 0 & 0 & 57.99 & 4.04 & $\mathbf{0}$ & 0 & 0 \\
NVAs & 0 & 0.19 & 0.49 & 0.09 & 0.23 & 0.11 & 0.05 & 10.92 & 0.01 & 4.30 & 3.26 & 0 & $\mathbf{7 9 . 2 4}$ & 1.11 \\
WBs & 0 & 0 & 0 & 0 & 0 & 0 & 0 & 0 & 0 & 0 & 0 & 0 & 0 & $\mathbf{1 0 0}$ \\
\hline
\end{tabular}

Table 4. Results of metrics applied at landscape level for the 14 classes of ecomosaics for the years 1985-2009. The suffix AM means "area-weighted mean".

\begin{tabular}{lccrrrr}
\hline & SHDI & SHEI & NP & Gyrate_AM & Shape_AM & Cohesion \\
\hline LC_14cl-1985 & 2.068 & 0.764 & 11111 & 54.039 & 7.962 & 98.352 \\
LC_14cl-2009 & 2.108 & 0.799 & 6611 & 70.955 & 7.870 & 98.612 \\
\hline
\end{tabular}

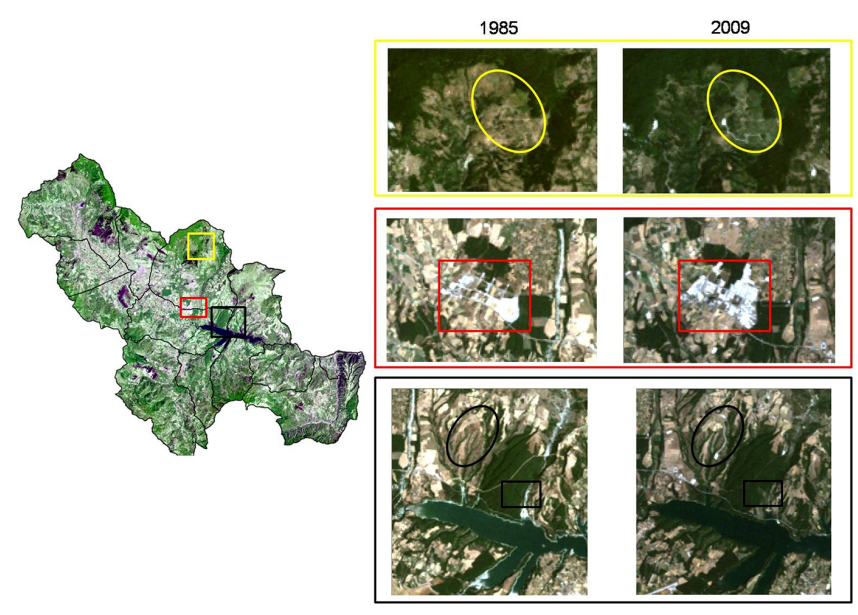

Figure 3. Example of changes occurred in the high Agri Valley in the period 1985-2009. Areas highlighted on the map on the left are zoomed in on the right by a Landsat 5-TM RGB composition ( $\mathrm{R}$ - band 3; G - band 2; B - band 1). In the yellow square an oil well and the service road with a wide herbaceous structure; in the red square the Viggiano industrial area where the Centro Olio Val d'Agri (COVA) is located; in the black square woodland variations close to Pertusillo Lake and new service roads.

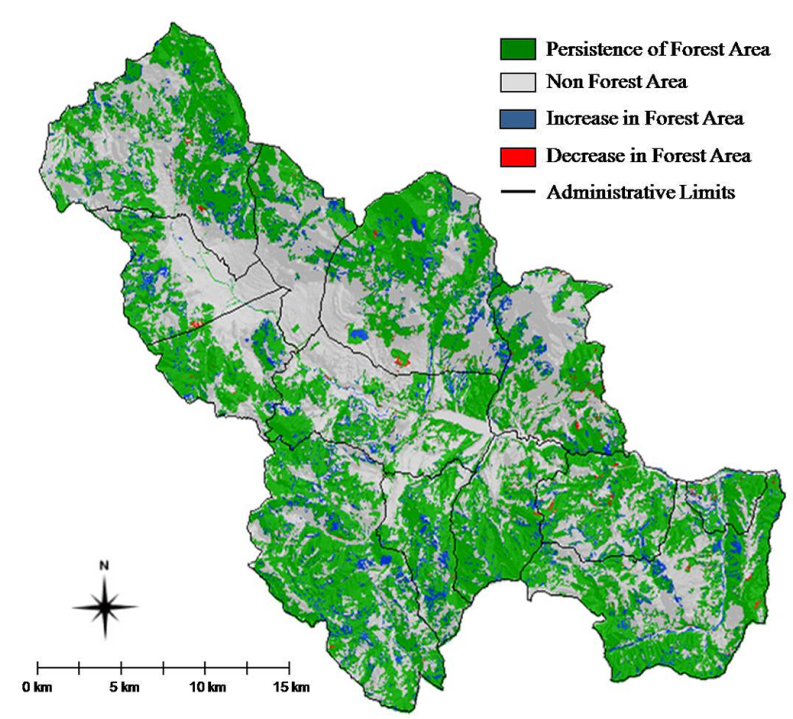

Figure 4. Forest area variation for the period 1985-2009.

The drop of NP and the notable growth of MPS express the reduction of the number of the patches and the increase of their sizes due to the forest transitions and the consequent rearrangement of the classes discussed in Sect. 4.1.1. The patch enlargement is not of similar magnitude in all the forest 

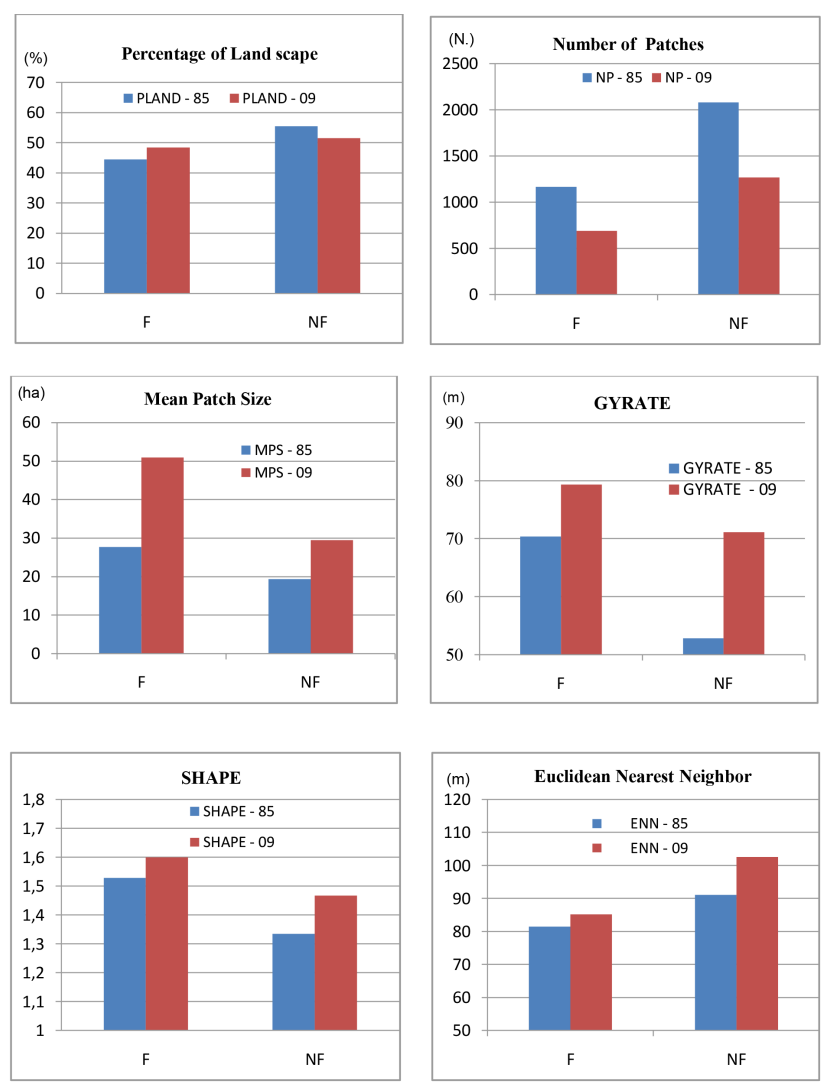

Figure 5. Histograms of the used metrics at class level for the forest/non-forest ecomosaic (1985-2009). For further details see Table 1.

covers but, interestingly, it is twice or more only for $\mathrm{Co}, \mathrm{Sh}$, $\mathrm{MH}$, and Ri classes.

Gyrate and shape generally increase for all the forest covers except for Pl that are characterized by very regular perimeters (shape 1.2 ) coherently with the particular man-made nature of this cover that is predominantly composed of arboriculture plantations and reforestation with exotic species.

Furthermore, the decrease in NP consequently results in great changes that affect positively patch size and compactness (MPS and gyrate indices), ultimately implying the increase in the distance between patches of the same class (ENN).

More broadly, the multitemporal analysis shows a tendency of forest areas to the expansion and the stabilization principally linked to the progressive disappearance of clearings within forest units (see in Fig. 7 two paradigmatic cases). This seems to be related to a more efficient management of cutting adopted in the last years and to the natural evolution of some forest types, particularly Co areas. Finally, in some areas we find an appropriate level of renaturalization due to the decrease of less densely vegetated areas with the expansion of mostly $\mathrm{Be}, \mathrm{Oa}$, and TOa covers.
We computed the index of cover density (D) to better highlight that fragmentation receded in the forest-dominated landscapes with the subsequent increase in vegetation density of forest covers (Fig. 8). The bar charts for the years 1985 and 2009 reveal a striking increase in vegetation cover density testified by higher values for the class $>80 \%$ reached by all the forest covers, a substantial stability for the medium-high class (50-80\%, except for Co and Sh covers for which we observe an appreciable increase), and a considerable reduction for the first two vegetation cover density classes $(<20 \%$ and $20-50 \%$ ).

\subsubsection{Binary ecomosaic: forest/non-forest}

On the basis of the simple landscape aggregation in forest/non-forest areas, the analysis performed at landscape level shows a substantial stability in diversity and evenness level (respectively SHDI and SHEI in Table 5). More precisely SHDI is characterized by quite low values as expected for very simple ecomosaics, whereas SHEI values can be considered very high, thus indicating a quite equal distribution in forest and non-forest classes.

We observe a marked decrease in the NP that is mainly caused by the natural evolution of afforested plantations (especially coniferous types) along with the choice of selective cutting in the broadleaved forests and the natural evolution of herbaceous and shrub covers. Therefore, patches become larger and more compact (gyrate) maintaining a very similar perimeter complexity (shape). Lastly, the physical connectedness level (cohesion) of the patches is constant over time and reaches very high values, close to the theoretical maximum of this metric, depicting a favorable scenario in terms of habitat quality for flora and fauna dispersal.

At class level, histograms reported in Fig. 5 illustrate a picture of improved landscape ecological value principally because of the enlargement of forest areas covering about $50 \%$ of the whole study area in 2009 (PLAND) with respect to 1985 (about $45 \%$ ). This determined a consistent decrease in the NP; i.e., patches occupy a wider area $(\sim 50$ ha, MPS $)$ and take irregular forms (higher value for shape index).

These observed changes do slightly increase connectivity inside the patches of forest areas (gyrate), which moves from about $70 \mathrm{~m}$ to about $80 \mathrm{~m}$ between the patch edges and the respective centroid, meaning a smaller exposure to external disturbance. Moreover also the ENN, computed between patches belonging to the same class, increases: $\sim 5$ and $\sim 10 \mathrm{~m}$, respectively, for forest and non-forest areas.

The main insight that can be inferred from this analysis is the important reduction in 2009 of the fragmentation level affecting forest areas in 1985. Similar results have been obtained by evaluating the Sh separately from the forest areas, confirming also for this cover a significant decrease of fragmentation level. 

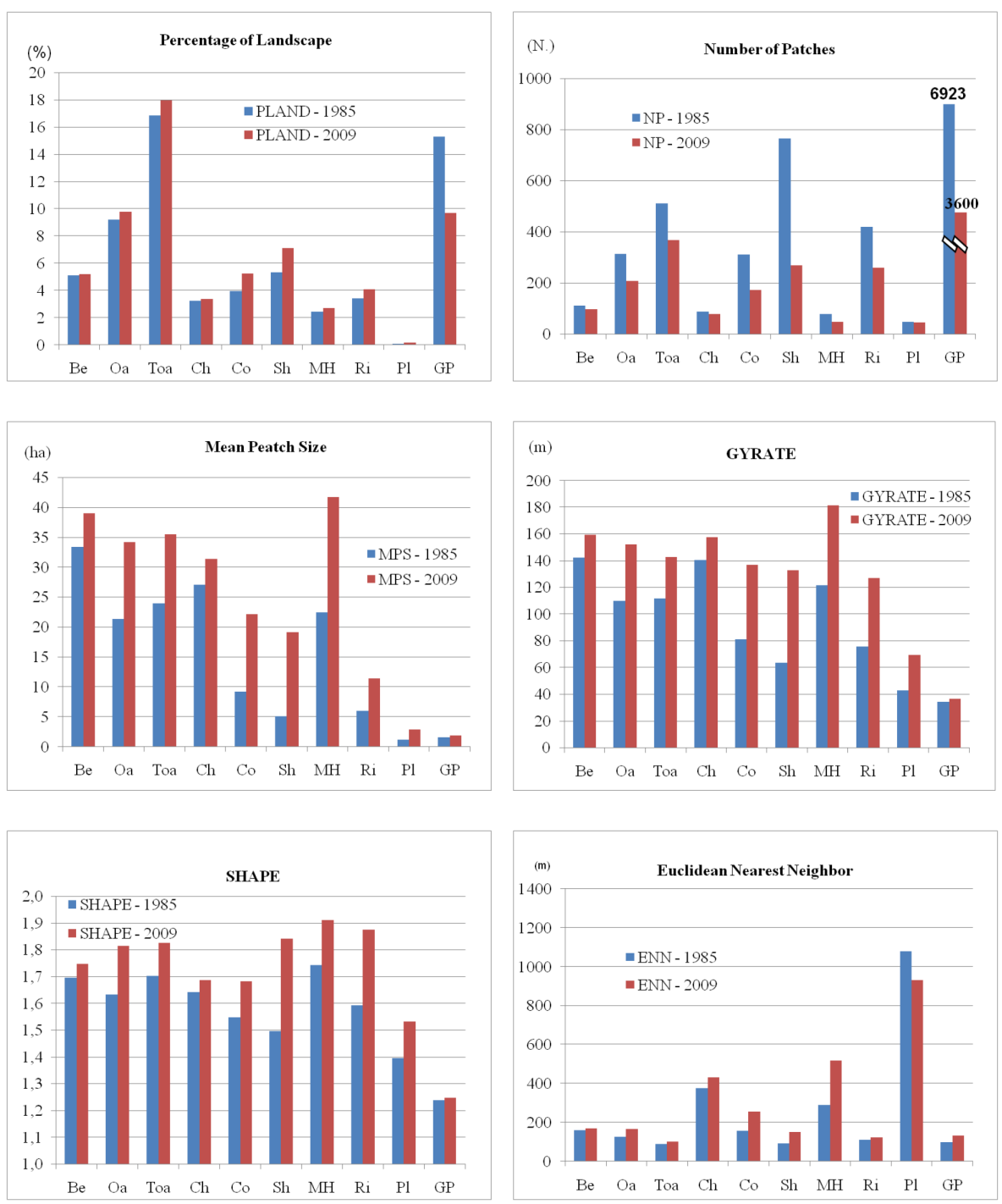

Figure 6. Histograms of the used metrics at class level for natural covers for the complex ecomosaics (1985-2009). For further details on landscape indicators see Table 1.

Table 5. Results of metrics applied at landscape level for the forest/non-forest ecomosaic for the years 1985-2009. The suffix AM means "area-weighted mean".

\begin{tabular}{lccrrrr}
\hline & SHDI & SHEI & NP & Gyrate_AM & Shape_AM & Cohesion \\
\hline LC_2cl-1985 & 0.687 & 0.991 & 3250 & 65.152 & 23.808 & 99.721 \\
LC_2cl-2009 & 0.693 & 0.999 & 1960 & 83.654 & 24.247 & 99.772 \\
\hline
\end{tabular}

\subsubsection{Complex ecomosaic: private vs. public forest tenure regimes}

The results illustrated in Sects. 4.2.1 and 4.2.2 do not suggest the existence of significant environmental or anthropogenic stresses in the area (e.g., absence of significance increments of artificial areas, bare and burnt lands, or fragmentation of natural lands). More interestingly, they evidence the basic role of efficient land management plans and current legislation.

In order to obtain further information on the influence of these determinants, we compared privately and publically managed forests by adopting the same metrics indicators of the previous elaborations at class level (see Figs. 9 and 10, which show the results of landscape metrics only for natural covers). 


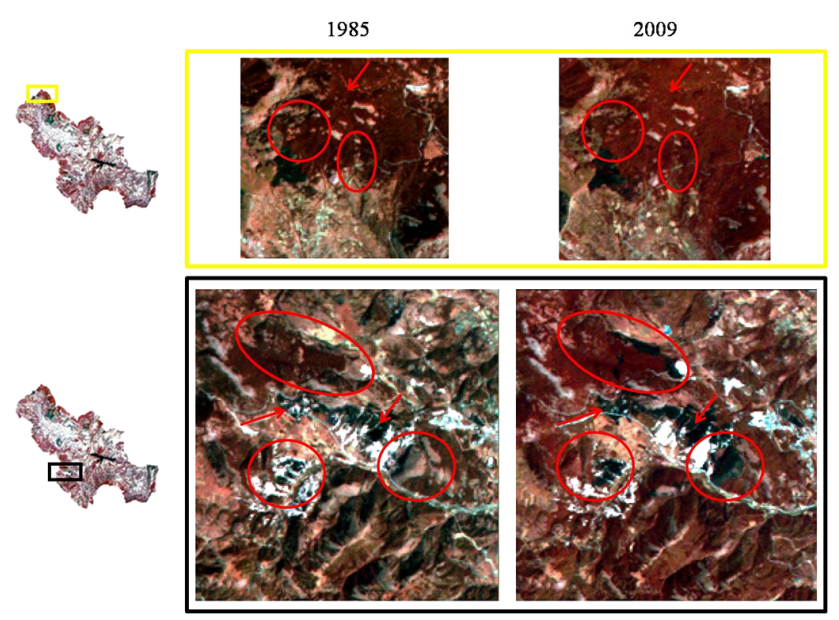

Figure 7. Examples of changes detected from 1985 and 2009 in the high Agri Valley: reduction of pastures and sparsely vegetated areas due to natural forest evolution of beeches $(\mathrm{Be})$ on the top and coniferous (Co) afforestation on the bottom. The RGB composition ( $\mathrm{R}$ - band 5; G - band 2; B - band 1) of Landsat 5-TM enhances broadleaved forests in dark red and coniferous forests in dark green.

In general, metrics indicators put into evidence a different behavior between privately and publically managed forest classes. The proportion of all the forest classes (PLAND) is increased in 2009 for both the analyzed forest tenure systems. However, in public domain larger increases are found for Co that include several past and recent afforestation plantings. This proves the effectiveness of the implemented compensatory actions devoted to improving the ecological value of marginal or degraded areas. Differently, within private forest ownership Oa, TOa, Sh, and Ri classes exhibit the highest rise in percentage composition. The growth of the Ri class is mainly due to the application of protection regulations involving fluvial areas (issued in 1985) through the removal of agricultural land from the vicinity of riparian buffers. This enabled the establishment and/or evolution of vegetated buffer zones that show higher compaction levels (gyrate) and a more complex patch perimeter (shape). Remarkably, Ri shows an opposite trend within public-ownership for the shape index that decreases between 1985 and 2009, similar to the behavior observed for $\mathrm{Ch}$ and MH. This last class, however, maintains an appropriate level of naturalness surpassed only by the corresponding value of Be.

\section{Conclusions}

This study focuses on land cover changes and forest landscape evolution (1985-2009) in a typical Mediterranean agroforestry system (high Agri Valley) experiencing a rapid escalation of anthropic activities linked to the exploitation of the largest European onshore oil reservoir.
We selected analysis tools suited for investigating the complex evolution of an area where the industrial acceleration greatly contributed to the modification of the socio-economic conditions, with some repercussions on the landscape structure. These tools can provide very valuable support to policy makers who face the urgent need to harmonize the unique natural heritage of the area with the demand of economic growth.

Land use trajectories and changes in landscape composition and configuration were captured by analyzing satellitederived land cover maps. The main transformations concerned are the splitting of most of the grass and pasture areas to the advantage of all the forest covers; the enlargement of riparian vegetation that benefited from ad hoc regulations concerning habitat protection and conservation; the expansion of artificial areas due to the building of a variety of infrastructure for oil and gas production and transport; and the abandonment of less-favored agricultural areas located at high elevation.

We estimated a net forest increase of $11 \%$ (about 5000 ha) during the time period 1985-2009, which coincides largely with the discovery and exploitation of the oil resources in the area.

Some of these quantitative findings about land cover variations confirm and integrate results obtained by independent studies concerning the reduction in UAA (utilized agricultural area) for all the municipalities involving particularly arable lands and permanent grass and pasture areas (Third and Sixth Italian Agricultural Census, corresponding to the period 1982-2010, http://dati-censimentoagricoltura. istat.it/); the increase in forest areas reported by the Regione Basilicata (2009) that delineates a strong expansion of forests in the period 1960-2000 through an estimation based on the Corine Land Cover 2000 (Büttner et al., 2002) and the 1960 Land Use Map of Italy (Vitelli, 2007); and the positive evolutionary tendency of the forest covers in the time span 19842010 highlighted by Mancino et al. (2014).

Forest covers do not appear to show macroscopic signs of anthropogenic disturbance. The use of landscape metrics indicators at both landscape and class level provided additional insight in understanding how forest areas have changed in the investigated period.

Briefly, all the forest classes increased their extent and have become generally more stable in functions and structure as a consequence of a larger patch size, a higher connectedness, a larger distance between similar patches, and a more irregular perimeter. This analysis was carried out also taking into account the forest tenure regimes (public and private) to elucidate some particular aspects arising from the different type of management.

The most interesting cases are represented by coniferous forests and riparian vegetation classes. Part of the coniferous forests was introduced in the 1950s to protect steep slopes from slumps and landslides. Especially in public areas, these forests have reached healthy conditions and an encouraging 

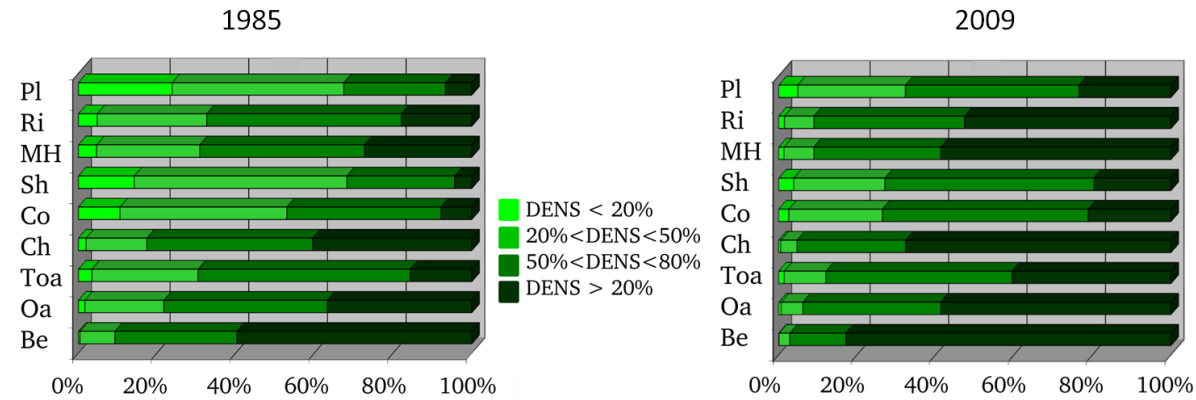

Figure 8. Bar chart displaying the segmentation of cover density per vegetation class. Values of vegetation density are derived from NDVI for the years 1985 and 2009.

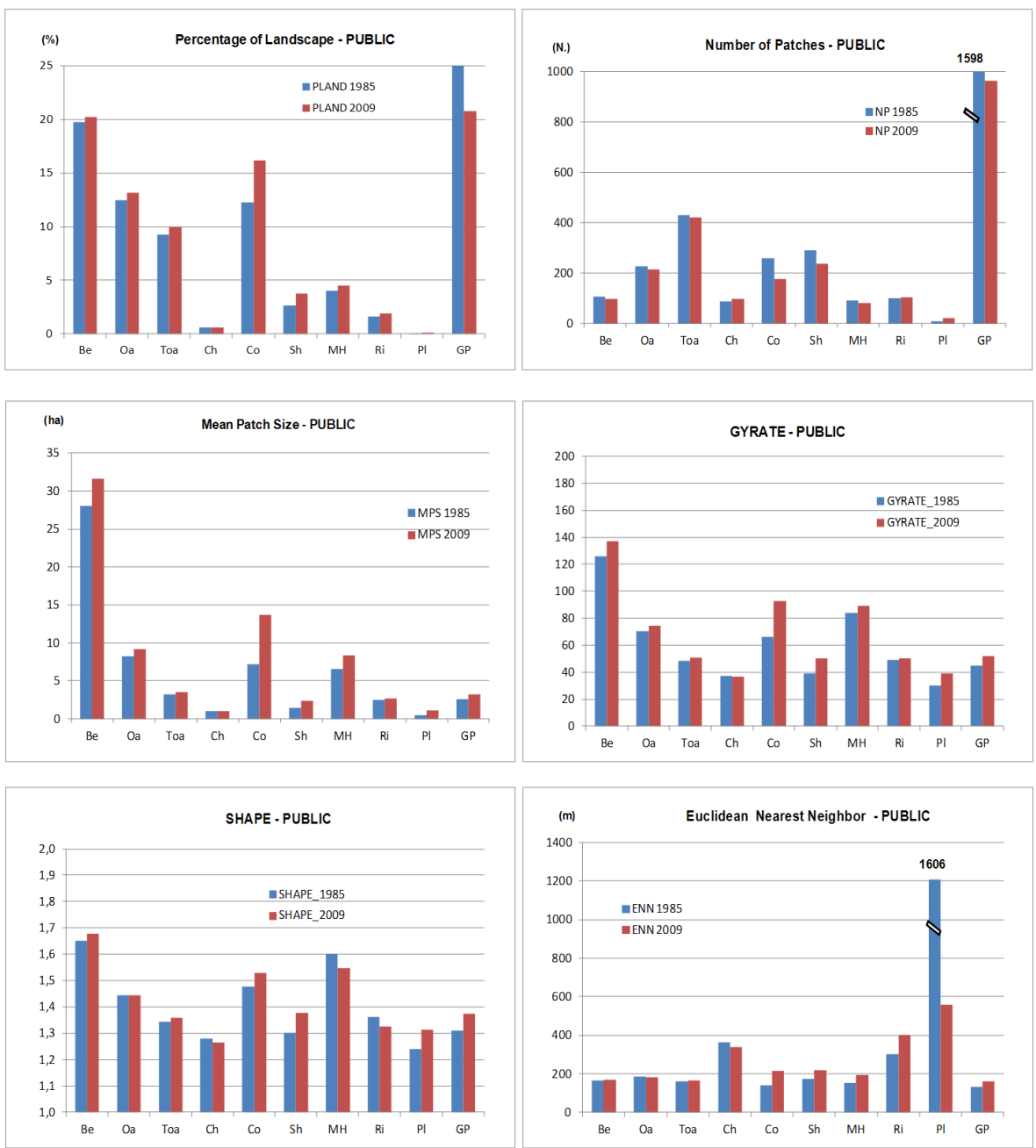

Figure 9. Histograms of the used metrics at class level for public-ownership natural covers for the complex ecomosaics (1985-2009). For further details on landscape indicators see Table 1.

level of naturalization, suggesting that these interventions have been successful. The riparian vegetation is characterized by a strong expansion and an appropriate arrangement very likely resulting from the application of legislation promoted in the past and recent years for protecting riparian vegetation (e.g., National Law 431/1985 on the protection of peculiar landscapes and environmental areas; EU Water Framework Directive 2000/60 - Integrated River Basin Management for Europe). This improvement of vegetation coverage along riverbanks activates a chain of positive effects in- 

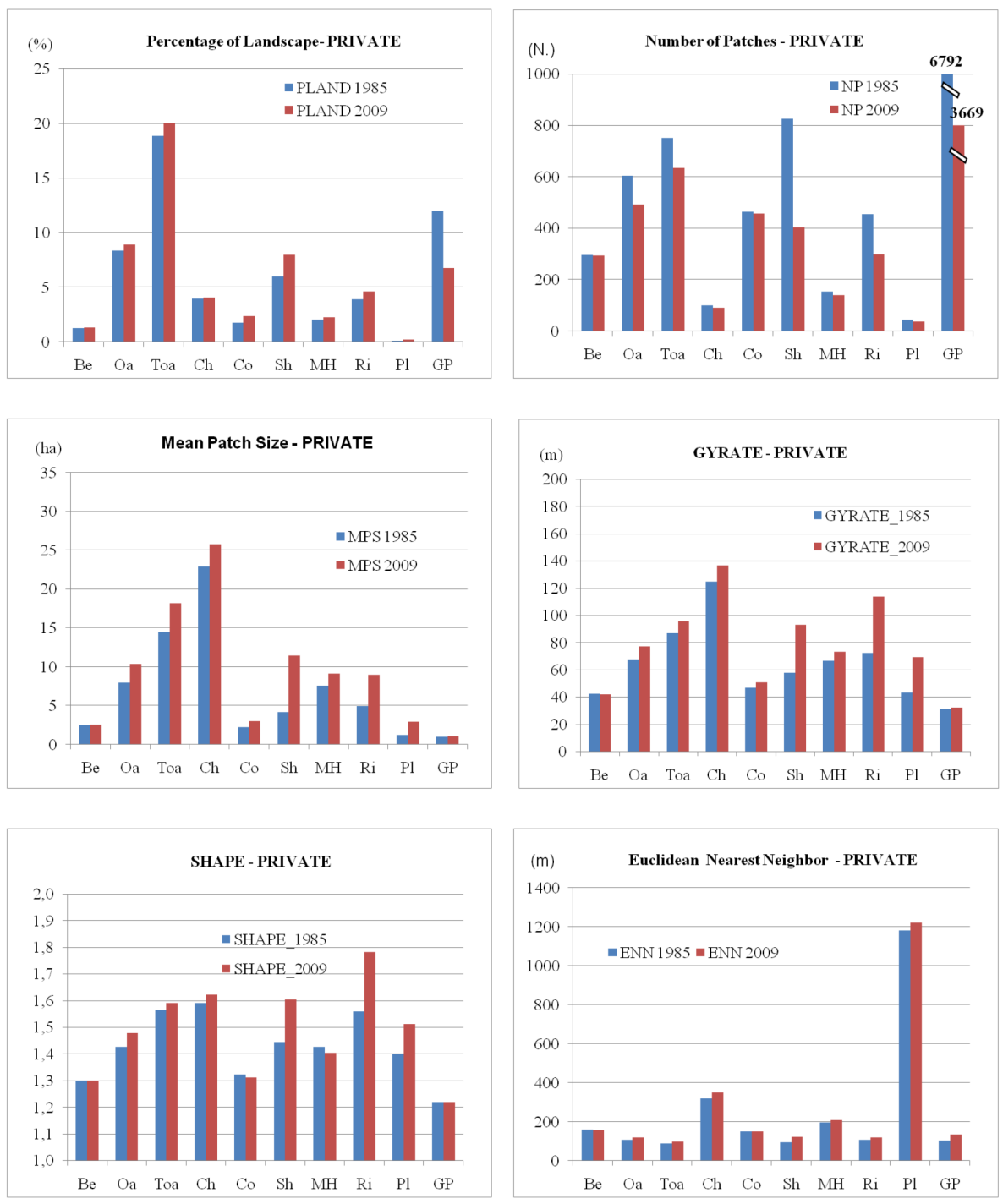

Figure 10. Histograms of the used metrics at class level for private-ownership natural covers for the complex ecomosaics (1985-2009). For further details on landscape indicators see Table 1.

cluding better water quality, greater ecological connectivity among river basins, and safer conditions for the biodiversity conservation of semi-aquatic species like otters (Morrow and Fischenich, 2000; Carranza et al., 2012; Carone et al., 2014).

Our results describe a very coherent picture where both in the public and private cases the current legislation seems to be correctly implemented. The main difference between the two regimes can be observed in the transitions from the grass and pasture to the coniferous and shrublands classes, which are characterized by near-inverse percentages $(4 \%$ toward Co and $18 \%$ toward Sh in the private sector; $14 \%$ toward Co and $4 \%$ toward $\mathrm{Sh}$ in the public sector). These differences are mostly ascribable to public reforestation interventions that in the private sector are more limited. Here grass and pasture mainly move toward shrublands that represent the next step in the ecological succession. Some other differences are sub- stantially determined by peculiarities in the local vegetation cover mosaics where clearings have been colonized by neighboring covers.

More in general, the observed tendency to the expansion for all the forest classes, confirmed by the increase of the cover density index $(D)$, appears to be linked to the gradual reduction of small clearings within forests and to the internal forest dynamics entailing a recolonization of pastures and herbaceous areas.

The benefits arising from the expansion and consolidation of forest covers in the high Agri Valley could encompass biodiversity, ecological stability, and biogeochemical cycles (IPCC, 2007).

Our results provide a coherent picture of the landscape evolution delineating not only the net increase-decrease balance of different covers but also how the area was trans- 
formed in terms of patch arrangement, size, connectivity, and their corresponding ecological meanings.

The main requisite of our monitoring strategy is its ability to detect "high-resolution changes" with low-cost data (free Landsat-TM data) and relatively simple investigations (hybrid classification and ecological metrics). These features make it suited for routine monitoring with performances that are competing with those of more expensive and complex data and analysis tools (e.g., extensive field surveys and photointerpretation or dedicated aerial campaign with hyperspectral sensors). Overall, considering the wide availability of satellite data characteristics (included the new EnMAP and Sentinel-2 mission), to respond to different requirements at the desired spatial and temporal resolution, the combined use of landscape metrics and satellite-derived ecomosaics represents a useful tool in operative contexts to optimize forest management plans in different bioregional contexts. In particular, the obtained results corroborate the necessity to define specific operative landscape metrics to assist policy and forest managers in fine-tuning measures concerning silvicultural activities and refine them in itinere by performing multitemporal analyses. Future research could also investigate the real consequences induced by forest expansion in terms of effects on ecosystem services such as biodiversity, productivity, filtering air, and water.

Acknowledgements. This activity was implemented in the framework of "Forest Management and Guidance Plans of High Agri Valley" financed by the local administration "Comunità Montana Alto Agri" and coordinated by the National Institute of Agricultural Economics of Basilicata (INEA). We thank Giuseppina Costantini and Silvia De Carlo (INEA) for ancillary data support.

Edited by: F. Vallianatos

Reviewed by: three anonymous referees

\section{References}

Antrop, M.: Landscape change and the urbanization process in Europe. Landsc. Urban. Plann., 67, 9-26, 2004.

Barsi, J. A., Hook, S. J., Schott, J. R., Raqueno, N. G., and Markham, B. L.: LANDSAT-5 Thematic Mapper Thermal Band calibration update, IEEE Geosci. Remote Sens., 4, 552-555, 2007

Blondel, J., Aronson, J., Boudiou, J. Y., and Boeuf, G.: The Mediterranean basin - biological diversity in space and time, Oxford University Press, Oxford, UK, 2010.

Borrelli, P., Modugno, S., Panagos, P., Marchetti, M., Schütt, B., and Montanarella, L.: Detection of harvested forest areas in Italy using Landsat imagery, Appl. Geogr., 48, 102-111, 2014.

Botequilha Leitato, A. and Ahern, J.: Applying landscape ecological concepts and metrics in sustainable landscape planning, Landsc. Urban. Plann., 59, 65-93, 2002.

Brivio, P. A., Lechi, G., and Zilioli, E.: Principi e metodi di telerilevamento, Ed. CittàStudi, UTET, Torino, 525 pp., 2006.
Büttner, G., Feranec, F., and Jaffrain, G.: Corine land cover update 2000. Technical report, Copenhagen: European Environment Agency, 2002.

Cantore, V., Iovino, F., and Pontecorvo, G.: Aspetti climatici e zone fitoclimatiche della Basilicata. Consiglio Nazionale delle Ricerche, Istituto di Ecologia e Idrologia Forestale, CNR (eds) Cosenza, 3-49, 1987.

Carone, M. T., Simoniello, T., Loy, A., and Carranza, M. L.: Combining habitat suitability models and fluvial functionality data for a multilayer assessment of riverine vulnerability, in: Models of the Ecological Hierarchy. Developments in Environmental Modelling, edited by: Jordan, F. and Jørgensen, S. E., 25, 417-431, 2012.

Carone, M. T., Guisan, A., Cianfrani, C., Simoniello, T., Loy A., and Carranza, M. L.: A multi-temporal approach to model endangered species distribution in Europe. The case of the Eurasian otter in Italy, Ecol. Model., 274, 21-28, 2014.

Carranza, M. L., D’Alessandro, E., Saura, S., and Loy, A.: Assessing habitat connectivity for semi-aquatic vertebrates. The case of the endangered otter in Italy, Landscape Ecol., 27, 281-290, 2012.

Chander, G. and Markham, B.: Revised LANDSAT-5 TM radiometric calibration procedures and postcalibration dynamic ranges, IEEE T. Geosci. Remote, 41, 2674-2677, 2003.

Collins, J. B. and Woodcock, C. E.: An assessment of several linear change detection techniques for mapping forest mortality using multitemporal Landsat TM data, Remove Sens. Environ., 56, 6677, 1996.

Costa, A., Madeira, M., Santos, J. L., Plieninger, T., and Seixas, J.: Fragmentation patterns of evergreen oak woodlands in Southwestern Iberia: Identifying key spatial indicators, J. Environ. Manage., 133, 18-26, 2014.

Costantini, G., De Carlo, S., Lettieri, T., Ferretti, F., De Meo, I., Frattegiani, M., Simoniello, T., Imbrenda, V., Carone, M. T., and Digilio, S.: Piano Forestale Territoriale di Indirizzo della Comunità Montana Alto Agri, "Forest Management and Guidance Plans of High Agri Valley", 187 pp., available at: http://www.inea.it/prog/osservatorio_foreste/it/view_file. php?action=doc $\&$ ServerFolder=osservatorio_foreste $/ \&$ id $=$ 2039\&ext=pdf\&data_type=application/pdf (last access: 10 July 2014), 2011.

FAO-UN, State of Mediterranean Forests 2013, 200 pp., available at: http://www.fao.org/docrep/017/i3226e/i3226e.pdf, last access: 10 July 2014.

Farcy, C.: Forest Planning in Europe: state of the art, international debates, emergent tools, in: Towards the Sustainable Use of Europe's Forests - Forest Ecosystem and Landscape Research: Scientific Challenges and Opportunities, edited by: Andersson. F., Birot, Y., and Päivinen, R., EFI, 49, 11-20, 2004.

Fichera, C. R., Modica, G., and Pollino, M.: Land Cover classification and change-detection analysis using multi-temporal remote sensed imagery and landsacpe metrics, Eur. J. Remote Sens., 45, 1-18, 2012.

Forest Europe, UNECE and FAO: State of Europe's Forests 2011. Status and Trends in Sustainable Forest Management in Europe, 2011.

Grove, A. T. and Rackham, O.: The nature of mediterranean Europe, An ecological history. Yale University Press, New Haven, CT, USA, 2001. 
Imbrenda, V., D’Emilio, M., Lanfredi, M., Macchiato, M., Ragosta, M., and Simoniello, T.: Indicators for the estimation of vulnerability to land degradation derived from soil compaction and vegetation cover, Eur. J. Soil Sci., 65, 907-923, 2014.

INEA - Istituto Nazionale di Economia Agraria, sede regionale per la Basilicata (a cura di), Carta forestale della Basilicata - Atlante "Forest Map of Regione Basilicata - Atlas", Lavello (PZ), 100 pp., 2006.

Ingegnoli, V.: Landscape Ecology: a Widening Foundation, Springer Verlag, Berlin, 357, 2002.

IPCC, Climate change 2007: the physical science basis. Contribution of Working Group I to the 4th Assessment Report of the IPCC, edited by: Solomon, S., Qin, D., Manning, M., Chen, Z., Marquis, M., Averyt, K. B., Tignor, M., and Miller, H. L., Cambridge University Press, Cambridge, UK and New York, NY, USA, 2007.

Jaeger, J. A. G.: Landscape division, splitting index, and effective mesh size: new measures of landscape fragmentation, Landsc. Ecol., 15, 115-130, 2000.

Kosmas, C., Kairis, O., Karavitis, C., Acikalin, S., Alcalá, M., Alfama, P., Atlhopheng, J., Barrera, J., Belgacem, A., SoléBenet, A., Brito, J., Chaker, M., Chanda, R., Darkoh, M., Ermolaeva, O., Fassouli, V., Fernandez, F., Gokceoglu, C., Gonzalez, D., Gungor, H., Hessel, R., Khatteli, H.,. Khitrov, N , Kounalaki, A., Laouina, A., Magole, L., Medina, L., Mendoza, M., Mulale, K., Ocakoglu, F., Ouessar, M., Ovalle, C., Perez, C., Perkins, J., Pozo, A., Prat, C., Ramos, A., Ramos, J., Riquelme, J., Ritsema, C., Romanenkov, V., Sebego, R., Sghaier, M., Silva, N., Sizemskaya, M., Sonmez, H., Taamallah, H., Tezcan, L., de Vente, J., Zagal, E., Zeiliguer, A., and Salvati, L.: An exploratory analysis of land abandonment drivers in areas prone to desertification, Catena, 128, 256-261, 2015.

Lafortezza, R., Coomes, D. A., Kapos, V., and Ewers, R. M.: Assessing the impacts of fragmentation on plant communities in New Zealand: scaling from survey plots to landscapes, Global Ecol. Biogeogr., 19, 741-754, 2010.

Lafortezza, R., Sanesi, G., and Chen, J.: Large-scale effects of forest management in Mediterranean landscapes of Europe, IForest, 6 , 342-346, 2013.

Lanfredi, M., Coppola, R., Simoniello, T., Coluzzi, R., D’Emilio, M., Imbrenda, V., and Macchiato, M.: Early identification of land degradation hotspots in complex Bio-Geographic Regions, Remote Sens., in press, 2015.

Mancino, G., Nolè, A., Ripullone, F., and Ferrara, A.: Landsat TM imagery and NDVI differencing to detect vegetation change: assessing natural forest expansion in Basilicata, southern Italy, IForest, 7, 75-84, 2014.

McGarigal, K., Tagil, S., and Cushman, S. A.: Surface metrics: an alternative to patch metrics for the quantification of landscape structure, Landscape Ecol., 24, 433-450, 2009.

McGarigal, K., Cushman, S. A. and Ene, E.: FRAGSTATS v4: Spatial Pattern Analysis Program for Categorical and Continuous Maps, Computer software program produced by the authors at the University of Massachusetts, Amherst, available at: http:// www.umass.edu/landeco/research/fragstats/fragstats.html, 2012.

Morrow, J. V. and Fischenich, C.: Habitat Requirements for Freshwater Fishes. EMRRP Technical Note Collection (ERDC TNEMRRP-SR-06), U.S. Army Engineer Research and Development Center, Vicksburg, 2000.
Nagendra, H., Munroe, D. K., and Southworth, J.: From pattern and process: Landscape fragmentation and the analysis of land use/cover change, Agr. Ecosyst. Environ., 101, 111-115, 2004.

Paletto, A., Ferretti, F., Cantiani, P., and De Meo, I.: Multifunctional approach in forest landscape management planning: an application in Southern Italy, For. Syst., 21, 66-80, 2012.

Paliwal, A. and Mathur, V. B.: Spatial pattern analysis for quantification of landscape structure of Tadoba-Andhari Tiger Reserve, Central India, J. For. Res., 25, 185-192, 2014.

Reddy, C. S., Jha, C. S., and Dadhwal, V. K.: Assessment and monitoring of long-term forest cover changes in Odisha, India using remote sensing and GIS, Environ. Monit. Assess., 185, 43994415, 2013.

Regione Basilicata: Sistema Ecologico Funzionale Territoriale. Regione Basilicata, Dipartimento Ambiente, Territorio e Politiche della Sostenibilità, Vol. 3, 2009.

Richards, J. A. and Jia, X.: Remote Sensing Digital Image Analysis: An Introduction, 4th Edn., Sprinter, ISBN 978-3-540-25128-6, 2006.

Rouse, J. W., Haas, R. H., Schell, J. A., Deering, D. W., and Harlan, J. C.: Monitoring the vernal advancements and retrogradation (green-wave effect) of nature vegetation, NASA/ GSFC, Final Report, 1974.

Salvati, L., Ranalli, F., and Gitas, I.: Landscape fragmentation and the agro-forest ecosystem along a rural-to-urban gradient: an exploratory study, Int. J. Sust. Dev. World, 21, 160-167, 2014.

Sano, M., Miyamoto, A., Furuya, N., and Kogi, K.: Using landscape metrics and topographic analysis to examine forest management in a mixed forest, Hokkaido, Japan: Guidelines for management interventions and evaluation of cover changes, Forest. Ecol. Manag., 257, 1208-1218, 2009.

Schindler, S., Poirazidis, K., and Wrbka, T.: Towards a core set of landscape metrics for biodiversity assessments: A case study from Dadia National Park, Greece. Ecol. Indic., 8, 502-514, 2008.

Simoniello, T., Carone, M. T., Coppola, R., D’Emilio, M., Grippa, A., Lanfredi, M., Liberti, M., and Macchiato, M.: Preliminary study to monitor land degradation phenomena throught landscape metrics, in: Proceedings of the 2nd Workshop of The EARSeL, Special Interest Group On Land Use and Land Cover, edited by: Braun, M., Bonn, Germany, 408-414, 2006.

Szaro, R., Langor, D., and Yapi, A. M.: Sustainable forest management in the developing world: science challenges and contributions, Landsc. Urban. Plann., 47, 135-142, 2000.

Tanrivermis, H.: Agricultural land use change and sustainable use of land resources in the Mediterranean region of Turkey, J. Arid. Environ., 54, 553-564, 2003.

Uuemaa, E., Roosaare, J., and Mander, U.: Landscape metrics as indicators of river water quality at catchment scale, Nord. Hydrol., 38, 125-138, 2007.

Vitelli, E.: Una bella realizzazione cartografica da parte dell'Amministrazione del Catasto italiano negli anni '50 e '60: "La carta dell'utilizzazione del suolo”, Rivista dell' Agenzia del Territorio, 2, 11-15, 2007.

Weber, C., Petropoulou, C., and Hirsch, J.: Urban development in the Athens metropolitan area using remote sensing data with supervised analysis and GIS, Int. J. Remote Sens., 26, 785-796, 2005. 